\title{
PENGARUH PART WHOLE METHOD TERHADAP TEKNIK DASAR PASSING BAWAH BOLA VOLI
}

\section{THE INFLUENCE OF THE ENTIRE SECTION OF THE METHOD ON THE BASIC ENGINEERING OF UNDER VOLY PASSING}

Trimizi $^{1)}$, Indra Iman ${ }^{2)}$, Elfry ${ }^{3)}$

${ }^{1}$ Pendidikan Jasmani, FKIP Universitas Tanjungpura

${ }^{2}$ SMK Negeri 5 Singkawang

${ }^{3}$ SMP Negeri 8 Singkawang

trijapran@yahoo.com

2 indraiman95@gmail.com

3uut.skw712@gmail.com

\begin{tabular}{l} 
Info Artikel \\
\hline Sejarah \\
Artikel: \\
Diterima (Oktober) \\
(2020) \\
Disetujui (November) \\
(2020) \\
Dipublikasikan \\
(November) (2020)
\end{tabular}

\section{Abstrak}

Penelitian ini dilatarbelakangi oleh teknik passing bawah pada bola voli siswa SMP Mandiri Pontianak yang belum berkembang, terlihat dari hasil masih banyak siswa yang berada di bawah standar nilai KKM. Tujuan dari penelitian ini adalah untuk mengetahui pengaruh metode Part Whole terhadap teknik dasar passing bawah bola voli pada siswa SMP Mandiri Pontianak. Metode penelitian yang digunakan adalah metode eksperimen, dengan menggunakan pendekatan Pre-eksperimental design dengan One Group Pre-test Post-test design. Populasi dalam penelitian ini adalah siswa kelas VIII SMP Mandiri Pontianak yang berjumlah 15 siswa. Dan sampel untuk penelitian ini adalah semua peserta didik. Teknik pengumpulan data yang digunakan adalah tes. Alat pengumpulan data yang digunakan adalah tes teknik passing bawah bola voli. Hasilnya Part Whole Methode berpengaruh terhadap teknik dasar underhand passing yang diperoleh thitung $(6.806)>$ ttabel $(2,114)$ dan nilai persentase 14,41\%. Berdasarkan hasil analisis dapat disimpulkan bahwa terdapat pengaruh yang signifikan Part whole Method terhadap teknik dasar passing bawah bola voli siswa SMP Mandiri Pontianak.

\begin{tabular}{l}
\hline Keywords: \\
\hline Part Whole \\
Method,
\end{tabular}

\section{Abstract}

This research was motivated by the under-passing technique of volleyball at SMP

Underhand Mandiri Pontianak students that had not yet developed, it was seen from the results that there were still many students who were below the KKM standard score. The purpose of this study was to determine the effect of the Part Whole method on the

Passing,

Volleyball basic techniques of volleyball passing under the students of SMP Mandiri Pontianak. The research method used is an experimental method, using a pre-experimental design approach with One Group Pre-test Post-test design. The population in this study were students of class VIII SMP Mandiri Pontianak, amounting to 15 students. And the sample for this research is all students. The data collection technique used was a test. The data collection tool used was a volleyball underpass technique test. The result is that the Part Whole Method has an effect on the basic techniques of underhand passing obtained by tcount (6.806)> ttable (2.114) and a percentage value of $14.41 \%$. Based on the results of the analysis, it can be concluded that there is a significant effect of Part Whole Method on the basic technique of passing volleyball under the students of SMP Mandiri Pontianak.

(C) 2020 Pendidikan Jasmani, Universitas Tanjungpura

alamat korespondensi

E-mail

No Handphone jln. Demang akub, komp. Puri kencana, no 39c, setapuk hulu, singkawang utara indraiman95@gmail.com

089694044480 


\section{PENDAHULUAN}

Pemilihan metode pembelajaran yang tepat, efektif dan efesien merupakan hal yang sangat penting dalam proses pembelajaran. Mengajar menggunakan part whole method merupakan metode mengajar gerak olahraga yang memiliki karakteristik yang berbeda. Penerapan metode pembelajaran tersebut didasarkan pada jenis keterampilan yang dipelajari memiliki unsur gerakan yang sederhana atau sulit. Menurut Widijoto yang dikutip oleh Ibnu Darmawan Dkk (2017:248) part whole method merupakan pendekatan motor learning yang mengajarkan aktivitas jasmani berdasarkan klarifikasi dan informasi yang diterima. Part whole akan sesuai untuk pembelajaran teknik dasar, yaitu dari bagianbagian teknik hingga teknik keseluruhan.

Menurut Widijoto Dalam skripsi Gleggo Cahyo Winbiyanto (2016:3) menyatakan part whole method merupakan metode yang dikembangkan dalam pendekatan motor learning. Part whole akan sesuai untuk pembelajaran teknik dasar, yaitu dari bagianbagian teknik hingga teknik secara keseluruhan part and whole merupakan metode pembelajaran yang dilakukan secara bertahap, dari pengenalan/pembelajaran teknik bagian hingga gabungan dari keseluruhan teknik bagian yang merupakan teknik gerakan yang utuh.

Pada dunia pendidikan ada pendidik dan peserta didik yang memiliki suatu kesatuan yang saling berhubungan dikarenakan keduanya adalah mahluk sosial. Sebagai makhluk sosial akan terjadi pengaruh timbal balik dimana setiap individu mendapatkan pengaruh dari individu lainnya. Pada dunia pendidikan, pendidik di tugaskan untuk meningkatkan pertumbuhan dan perkembangan peserta didik dengan cara memberikan pelayanan, dorongan dan bantuan dengan mendalami belajar tahap demi tahap untuk memperoleh kepandaian, keterampilan, dan pembentukan karakter peserta didik.

Peningkatan pertumbuhan dan perkembangan peserta didik didukung berdasarkan aktivitas jasmani yang dilakukan peserta didik setiap individu. Dunia pendidikan memfasilitasi aktivits jasmani peserta didik dengan memasukan mata pembelajaran pendidikan jasmani di sekolah dengan harapan Pendidikan jasmani memiliki aspek nilai fungsional yang terkandung didalammnya seperti aspek kognitif, psikomotorik dan afektif.

Menurut Dini Rosdiani ( 2012: 23) Pendidikan jasmani adalah proses pendidikan yang memanfatkan aktivitas jasmani yang direncanakan secara sistematik bertujuan untuk mengembangkan dan meningkatkan individu secara organik, neoromuskuler, perseptual, kognitif, dan emosional, dalam kerangka sistem pendidikan nasional.

Pendidikan jasmani bukan hanya dekorasi atau ornamen yang ditempel pada program sekolah sebagai alat untuk membuat anak sibuk. Tetapi pendidikan jasmani adalah bagian penting dari pendidikan. Pendidikan jasmani yang diarahkan dengan baik, peserta didik akan terlibat dalam aktivitas jasmani yang teratur untuk mengembangkan hidup sehat peserta didik. Peserta didik akan terlibat langsung dalam hasil belajar yang ingin di capai, pencapaiannya harus ditelaah secara menyeluruh sebelum menetapkan materi pembelajaran pendidikan jasmani pada setiap jenjangnya.

Pembelajaran pendidikan jasmani dapat berjalan lancar \& sukses ditentukan oleh guru, peserta didik, sarana prasarana, media atau metode yang digunakan. Pembelajaran adalah suatu kombinasi yang tersusun meliputi unsur-unsur manusiawi, material, fasilitas, perlengkapan, dan prosedur yang saling mempengaruhi mencapai tujuan pembelajaran.

Proses pembelajaran perlu direncanakan dan dirancang secara optimal agar dapat memenuhi harapan dan tujuan dalam pencapaian hasil belajar. Proses pembelajaran bukan hanya sekedar transfer ilmu dari pendidik ke peserta didik, melainkan sesuatu proses pembelajaran yang baik sangat didukung dengan adanya sarana prasarana mendukung, maka diperlukan suatu metode atau upaya untuk meningkatkan keterampilan 
gerak dan kejenuhan belajar dan memudahkan peserta didik mempelajarinya.

Membuat pembelajaran menjadi lebih menyenangkan dan dapat mempelancar suatu proses pembelajaran adalah tugas seorang guru. Di sekolah-sekolah masih banyak kekurangan sarana dan prasarana, maka dibutuhkan seorang guru memiliki kreatifitas yang tinggi.

Pendidikan jasmani memiliki beragam macam materi-materi pokok yang diajarkan di sekolah berdasarkan kurikulum yang diterapkan. Salah satunya adalah permainan bola besar yaitu permainan bola voli. Bola voli memiliki gerak dan teknik dasar yang dipelajari. Dalam materi bola voli peserta didik dituntut untuk mengetahui keterampilan gerak dasar salah satunya adalah passing bawah. Di dalam passing bawah ada beberapa tahapan yang harus dipelajari yaitu: tahap persiapan, tahap pelaksanaan, dan gerak lanjutan. Jika tahapan tersebut bisa dipelajari dengan baik dan benar, maka kualitas passing akan lebih baik pula.

Berdasarkan data yang dilihat dari daftar penilaian pada aspek keterampilan passing bawah bolavoli pada peserta didik kelas VIII SMP MANDIRI Pontianak, dari 15 siswa yang melakukan passing bawah hanya 6 siswa yang mencapai KKM penilaian dengan KKM 75, 9 siswa lainnya nilai keterampilan masih berada di bawah standar KKM. Ini dikarenakan keterampilan teknik dasar passing bawah bola voli yang dilakukan siswa pada tahap persiapan, tahap pelaksanaan serta gerak lanjutan belum sesuai dengan tahapan-tahapan teknik dasar passing bawah bolavoli, sehingga perkenaan bola pada tangan tidak tepat, posisi kaki yang tidak benar, serta ayunan tangan yang tidak sempurna. Untuk mengatasi masalah di atas penulis menggunakan part whole method yang diharapkan dapat mempelancar kegiatan pembelajaran. Berdasarkan permasalahan di atas bahwa part whole method sangat sesuai digunakan untuk mengajarkan teknik secara bagian hingga keseluruhan agar siswa dapat melakukan teknik yang baik.

Menurut Harsono Dalam skripsi Nina Yuniarti (2016:42) pada umumnya guru mengajarkan suatu teknik dengan part method, hal ini disebabkan karena:

(1) siswa belum banyak tahu mengenai cara melaksanakan teknik atau keterampilan.

(2) agar siswa melakukan teknik sesuai dengan keinginan guru.

\section{METODE PENELITIAN}

Adapun metode yang digunakan dalam penelitian ini adalah kuantitatif. Menurut Sugiyono (2017:11), Metode kuatitatif diartikan sebagai metode penelitian yang berlandaskan pada filsafat positivisme, digunakan untuk meneliti pada populasi atau sampel tertentu, pengumpulan data menggunakan instrumen penelitian, analisis data bersifat kuantitatif/statistik, dengan tujuan untuk menguji hipotesis yang telah ditetapkan.

Adapun bentuk penelitian yang digunakan adalah eksperimen. Menurut Fathoni (2011: 99) metode eksperimen berarti percobaan untuk mempelajari pengaruh dari variabel tertentu terhadap variabel yang lain, melalui uji coba dalam kondisi khusus yang sengaja diciptakan. Sedangkan menurut Sugiyono (2017:39) metode eksperimen dapat diartikan sebagai metode penelitian yang digunakan untuk mencari pengaruh perlakuan tertentu terhadap yang lain dalam kondisi yang terkendali. Jadi, penelitian ini bertujuan untuk mengetahui pengaruh yang terjadi.

Untuk desain penelitian, eksperimen yang lebih spesifik, penulis menggunakan model penelitian bentuk pre-eksperimental design yaitu one group pretest-posttest design. Adapun desain yang dimaksud adalah sebagai berikuit :

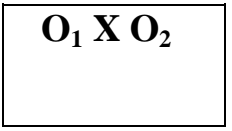

Sumber : Arikunto, (2013:124)

Gambar 1. Rancangan Penelitian

Keterangan :

$\mathrm{O}_{1}=$ Nilai pretest(sebelum di berikan pembelajaran)

$\mathrm{X}=$ Perlakuan 
$\mathrm{O}_{2}=$ Nilai post test(setelah diberikan pembelajaran)

Menurut Sugiyono (2017: 117), populasi adalah wilayah generalisasi yang terdiri atas: obyek/ subyek yang mempunyai kualitas dan karakteristik tertentu yang diterapkan oleh penulis untuk dipelajari dan kemudian ditarik kesimpulannya Adapun populasi pada penelitian ini adalah keseluruhan siswa kelas VIII yang terdiri dari 1 kelas berjumlah 15 siswa pada sekolah SMP Mandiri Pontianak. Adapun teknik pengambilan sampel pada penelitian ini menggunakan teknik Total sampling dimana seluruh siswa kelas VIIU dijadikan sampel dalam penelitian. Adapun uji normalitas dalam penelitian ini menggunakan pengujian normalitas chikaudrat dengan bantuan SPSS 20.0 for Windows.

\section{HASIL DAN PEMBAHASAN Hasil}

Penelitian ini berlangsung sebanyak 8 kali pertemuan, penulis menggunakan kelas VIII di SMP Mandiri Pontianak dengan jumlah 15 peserta didik, sebelum memberikan perlakuan menggunakan metode. Kelas tersebut terlebih dahulu diberikan tes awal (pretest) untuk mengetahui deskripsi teknik passing bawah bola voli siswa sebelum diterapkan Part Whole Method, kemudian diterapkan Part Whole Method terhadap teknik passing bawah bola voli, kemudian diberi tes akhir (posttest) untuk mengetahui rata-rata hasil belajar setelah diterapkan part whole method terhadap teknik passing bawah bola voli.

Pengolahan data hasil penelitian berdasarkan hasil tes yang telah dilakukan terhadap hasil belajar yang dimiliki peserta didik dengan analisis uji pengaruh. Hasil analisis data dibandingkan dan diambil kesimpulan untuk mengetahui hasil penelitian sebagai jawaban dari masalah penelitian. Berdasarkan hasil penelitian adapun data penelitian yang diperoleh adalah sebagai berikut.

Berikut ini adalah gambaran hasil pengolahan data pretest dan posttest Part Whole Method terhadap teknik passing bawah bola voli pada peserta didik SMP Mandiri Pontianak dideskripsikan pada tabel dibawah ini:

Tabel 1. Perhitungan Rata-rata $(\overline{\mathbf{x}})$ dan Standar Deviasi (SD) Data Pretest dan Posttest Part Whole Method terhadap Teknik Passing Bawah Bola Voli

\begin{tabular}{llllllll}
\hline $\begin{array}{l}\text { Teknik } \\
\text { Dasar } \\
\text { Passing }\end{array}$ & Perlakuan & $\begin{array}{l}\text { Rata- } \\
\text { rata }\end{array}$ & SD & $\begin{array}{l}\text { Skor } \\
\text { Maksimal }\end{array}$ & $\begin{array}{l}\text { Skor } \\
\text { Minimal }\end{array}$ & Modus & Median \\
\cline { 2 - 8 } Bawah & Pretest & 73,53 & 7,772 & 86 & 60 & 73 & 80 \\
& Posttest & 81,13 & 4,611 & 93 & 73 & 73 & 86 \\
\hline
\end{tabular}

Dari tabel tersebut, terlihat deskripsi hasil Pretest dengan nilai rata-rata 73,53 , standar deviasi 7,772, skor maksimal 86, skor minimal 60, modus 73 dan median 80 . Sedangkan hasil Posttest diperoleh nilai ratarata 81,13 , standar deviasi 4,611, skor maksimal 93, skor minimal 73, modus 80 dan median 86. Adapun hasil rata-rata Pretest Posttest ditampilkan dalam bentuk diagram dapat dilihat pada gambar dibawah ini: 


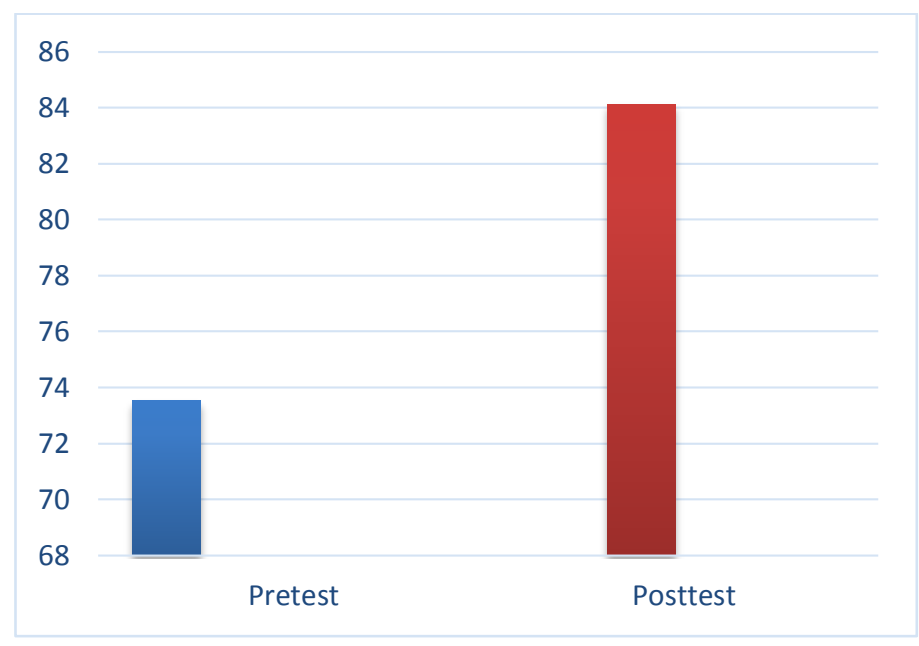

Gambar 2. Hasil Kemampuan Teknik Passing Bawah Bola Voli

Uji normalitas data dimaksudkan untuk memperlihatkan bahwa data pretest dan posttest berdistribusi normal. Teknik yang digunakan untuk menguji normalitas data pretest dan posttest yaitu dengan $\mathrm{Uji}$ chikuadratatau chi-square dan taraf signifikansi 0,05 atau $5 \%$. Pengujian chi-squere dibantu dengan menggunakan SPSS 20.0 for Windows.
Kriteria pengambilan keputusan dalam uji normalitas ialah: (1) Jika nilai chi kuadrat $\left(\mathrm{X}^{2}\right)$ hitung $<$ chi kuadrat $\left(\mathrm{X}^{2}\right)$ tabel maka data berdistribusi normal. (2) Jika nilai chi kuadrat $\left(X^{2}\right)$ hitung $>\quad$ chi kuadrat $\left(\mathrm{X}^{2}\right)$ tabelmaka data tidak berdistribusi normal. Berdasarkan analisis yang telah dilakukan, didapat hasil pada tabel:

Tabel 2. Data Hasil Uji Normalitas Pretest dan Posttest

\begin{tabular}{cccc}
\hline Teknik Dasar & Indikator & Signifikansi & Keterangan \\
\cline { 2 - 4 } Passing Bawah & Pretest & $4,667<9,49$ & Normal \\
Bola Voli & Posttest & $2,800<5,99$ & Normal \\
\hline
\end{tabular}

Berdasarkan hasil output uji normalitas menggunakan Uji chi squere tertera dilampiran, nilai signifikansi data pretest posttest sebesar 4,667 dan 2,800 nilai tersebut lebih kecil dari chi kuadrat tabel dengan taraf signifikan 0,05. Berdasarkan kriteria pengambilan keputusan, maka data dari hasil pretest dan posttest berasal dari populasi yang berdistribusi normal. Uji homogenitas berguna menguji kesamaan sampel yaitu seragam atau tidak varian sampel yang diambil dari populasi. Kiteria homogenitas jika $F_{\text {hitung }}<\mathrm{F}_{\text {tabel }}$ maka dinyatakan homogen dan sebaliknya jika nilai $F_{\text {hitung }}>F_{\text {tabel }}$ maka dinyatakan tidak homogen. Hasil uji homogenitas dapat dilihat pada tabel berikut:

Tabel 3. Hasil Uji Homogenitas

\begin{tabular}{ccc}
\hline Teknik Dasar Passing & Signifikansi & Keterangan \\
\cline { 2 - 3 } Bawah Bola Voli & $2,84<4,60$ & Homogen \\
\hline
\end{tabular}


Berdasarkan tabel diatas data hasil passing bawah peserta didik SMP Mandiri Pontianak diperoleh nilai signifikan 2,84< ,60 sehingga dapat disimpulkan bahwa varians bersifat homogen.

Pengujian hipotesis dilakukan untuk mengetahui ada tidaknya pengaruh Part Whole Method terhadap teknik passing bawah bola voli pada peserta didik SMP Mandiri Pontianak, pengujian menggunakan uji t-test. Pengujian hipotesis uji t-test menggunakan data pretest dan posttest dengan kriteria: (1) Jika $t_{\text {hitung }}>t_{\text {tabel }}$ maka $\mathrm{H}_{\mathrm{a}}$ diterima. (2) Jika $t_{\text {hitung }}<t_{\text {tabel }}$ maka $\mathrm{H}_{\mathrm{a}}$ ditolak. Berdasarkan analisis yang telah dilakukan, didapat hasil pada tabel:

Tabel 4. Hasil Uji T-test Pretest dan Posttest

\begin{tabular}{|c|c|}
\hline \multirow{2}{*}{$\begin{array}{l}\text { Pengaruh Part } \\
\text { Whole Method }\end{array}$} & Indikator \\
\hline & T hitung \\
\hline $\begin{array}{l}\text { Berdasarkan perhi } \\
6,806 \text {. Kemudian } \\
\text { dengan melihat tal } \\
\mathrm{n}-1=15-1=14, \mathrm{~m} \\
2,144 \text {. Hasil p } \\
\text { hipotesis } \mathrm{H}_{\mathrm{a}} \mathrm{d} \\
\text { pengaruh Part Wh } \\
\text { dasar Passing bav } \\
\text { didik SMP Mandir }\end{array}$ & $\begin{array}{l}\text { liatas } t_{\text {hitung }} \text { sebesar } \\
\text { encari } t_{\text {tabel }} \text { yakni } \\
\alpha=0,05 \text { dan } \mathrm{dk}= \\
\text { apatlah } \mathrm{t}_{\text {tabel }} \text { sebesar } \\
\text { tersebut berarti } \\
\text { artinya terdapat } \\
o d \text { terhadap teknik } \\
\text { voli pada peserta } \\
\text { ak. }\end{array}$ \\
\hline
\end{tabular}

\section{Pembahasan}

Berdasarkan penelitian yang sudah dilakukan, diperoleh hasil yang menyatakan terdapat pengaruh Part Whole Method terhadap teknik passing bawah bola voli pada peserta didik kelas VIII SMP Mandiri Pontianak. Aktivitas metode Part Whole yang digunakan yaitu terdapat dua perlakuan dalam program latihan dengan nilai tes awal (pretest) untuk mengetahui rata-rata hasil praktek peserta didik sebelum diterapkan Part Whole Method sebesar 74 yang termasuk dalam kategori gagal dan rata-rata hasil praktek sesudah diterapkan Part Whole Method sebesar 84 yang termasuk dalam kategori baik dengan nilai persentase sebesar $14,41 \%$. Hal ini berarti rata-rata hasil teknik dasar passing bawah peserta mengalami peningkatan kearah yang lebih baik.

Part whole method merupakan metode gabungan dari metode bagian dan metode keseluruhan yakni cara pendekatan dimana mula-mulapeserta didik diarahkan untuk

\begin{tabular}{cc} 
Signifikansi & Keterangan \\
\hline $6,806>2,114$ & $\mathrm{H}_{\mathrm{a}}$ diterima \\
$\begin{array}{l}\text { mempraktekkan secara keseluruhan rangkaian } \\
\text { gerakan kemudian mempraktekkan secara }\end{array}$
\end{tabular}

keseluruhan rangkaian gerakkan. Metode ini untuk mempermudah peserta didik dalam menguasai berbagai teknik dasar karena teknik dasar diajarkan secara mendetail sehingga pada bagian yang paling sulit peserta didik mampu melakukannya.

Hal-hal yang dilakukan adalah: (1) melakukan pretest teknik dasar passing bawah bola voli, (2) memberikan perlakuan sebanyak 8 kali pertemuan, dan (3) melakukan posttest teknik dasar passing bawah, sehingga dapat diketahui hasil teknik dasar passing bawah bola voli berpengaruh atau tidak setelah diberi latihan passing bawah menggunakan Part Whole Method.

Kemudian sebelum melakukan uji hipotesis, dilakukan uji normalitas menggunakan uji chi-kuadrat dengan taraf signifikansi 0,05 menghasilkan signifikansi sebesar data pretest - posttest sebesar 9,663 nilai tersebut lebih kecil dari 11,070 dan dinyatakan data berdistribusi normal.

Pengujian hipotesis menggunakan uji ttest menggunakan data pretest dan posttest menghasilkan $t_{\text {hitung }}(6,806)>t_{\text {tabel }}(2,144)$, maka hipotesis $\mathrm{H}_{\mathrm{a}}$ diterima, maka dapat disimpulkan bahwa adanya pengaruh Part Whole Method terhadap teknik dasar passing bawah bola voli terhadap peserta didik kelas VIII SMP Mandiri Pontianak.

Hasil dari penelitian ini dapat diambil kesimpulan bahwa Part Whole Method dapat 
meningkatkan teknik dasar passing bawah bola voli pada siswa kelas VIII SMP Mandiri Pontianak yang membawa pengaruh baik. Metode ini merupakan latihan yang efisien dalam meningkatkan kemampuan teknik siswa dalam bermain bola voli. Passing bawah merupakan salah satu kunci bentuk pertahanan dalam suatu pertandigan, karena jika passing bawahnya tidak baik maka akan sulit untuk mengoper bola dengan baik juga.

Menurut Erianti (2011: 159), passing bawah merupakan elemen utama untuk mempertahankan regu dari serangan lawan (bola yang datangnya terlalu keras dan sulit dimainkan dengan passing bawah). Maka dengan Part Whole Methode, maka teknik passing bawah peserta didik kelas VIII SMP Mandiri dilatih secara bertahap, berulangulang dan rutin agar mencapai hasil yang memuaska dalam melakukan teknik passing bawah bola voli.

\section{SIMPULAN}

\section{Kesimpulan}

Berdasarkan hasil penelitian dan pembahasan sebelumnya dapat disimpulkan bahwa ada pengaruh Part Whole Method terhadap teknik passing bawah bola voli pada peserta didik kelas VIII SMP Mandiri Pontianak dengan hasil nilai $\mathrm{T}_{\text {hitung }}(9,051)>$ $\mathrm{T}_{\text {tabel }}(2,144)$. Maka hipotesis $\mathrm{H}_{\mathrm{o}}$ ditolak dan $\mathrm{H}_{\mathrm{a}}$ diterima dan hasil persentase peningkatan sebesar $13,49 \%$.

\section{DAFTAR RUJUKAN}

Abdullah, Arma. (2000). Dasar-dasar Pendidikan Jasmani. Jakarta: Proyek Pembinaan dan Peningkatan Mutu Tenaga Kependidikan.

Arikunto, Suharsimi. (2013). Prosedur Penelitian Suatu Pendekatan Praktik. Jakarta: PT. Rineka Cipta.

Bangun, Syahputra Riady. (2011). [online]. Teknik Dasar Bermain Bola Voli. Terdapat www.kidinglagutul.blogspot.com, diakses 12 Oktober 2018.

Erianti. (2011). Buku Ajar Bola voli. Padang: Sukabina Press.

Fathoni, Abdurrahmat. (2011). Metodologi Penelitian dan Teknik Penyusunan Skripsi. Jakarta: PT. Rineka Cipta.

Guru, Tim Abdi. (2007). Penjas Orkes. Jakarta : PT Gelora Aksara Pratama.

Harsono. (1988). Coaching dan Aspek-aspek Psikologis dalam Coaching. Jakarta: Departemen Pendidikan dan Kebudayaan DIRJEN Pendidikan Tinggi Proyek Pengembangan Lembaga Pendidikan Tenaga Kependidikan.

Majid, Abdul. (2016). Strategi Pembelajaran. Bandung : PT Remaja Rosdakarya.

Muhajir. (2007). Pendidikan Jasmani Olahraga dan kesehatan. Jakarta: PT. Gelora Aksara Pratama.

Rosdian, Dini. (2012). Model Pembelajaran Langsung dalam Pendidikan Jasmani dan Kesehatan. Bandung: Alfabeta.

Sugiyono. (2017). Metode Penelitian Kuantitatif Kualitatif dan $R$ and $D$. Bandung: Alfabeta.

Sutrisno. (2007). Permainan Bola Voli

Berprestasi. Jakarta: PT Musi Perkasa Utama. Viera, Barbara L dan Fergusson Bonnie Jill. (2004). Bola Voli Tingkat Pemula. Jakarta: PT. Raja Grafindo Persada.

Widijoto, Heru. (2010). Strategi Pembelajaran Pendidikan Jasmani Olahraga dan Kesehatan. Malang: Universitas Negeri Malang.

Winbiyanto, Gleggo Cahyo. (2016). Pengaruh Metode Part And Whole Terhadap Hasil Belajar Teknik Dasar Servis Bawah Bola Voli Pada Ekstrakurikuler Bola Voli di SMP N 4 
Pacitan. Yogyakarta: Universitas Negeri Yogyakarta.

Winbiyanto, Gleggo Cahyo. (2016). Pengaruh Metode Part And Whole Terhadap Hasil Belajar Teknik Dasar Servis Bawah Bola Voli Pada Ekstrakurikuler Bola Voli di SMP N 4 Pacitan. Yogyakarta: Universitas Neegeri Yogyakarta.

Yuniarti, Nina. (2016). Pengaruh Metode Bagian dan Metode Keseluruhan (Part Method an Whole Method) dalam Pembelajaran Penjas untuk Meningkatkan Kemampuan Konsep Gerak Anak Tunanetra Kelas IV di SLB A. Yaketunis Yogyakarta. Yogyakarta: Universitas Yogyakarta. (Terbit). 